\title{
Positive relationships in community youth development organisations: A reflection on changing organisational relationships in Girl Guides Australia
}

\author{
Robyn Gibbs
}

Email: kuliar.rg@gmail.com

\section{Abstract}

When relationships within a community organisation are productive, staff are more likely to be happy, to understand and to be effective in their role. In youth-focused organisations delivering volunteer-led youth programs, a productive organisational relationship is essential to ensure effective recruitment, development and retention of staff, and the delivery of quality programs. This article provides a unique examination of the organisational relationships within Girl Guides Australia, between the volunteers who govern the organisation and those who deliver the youth program. The results of an extensive Australia-wide review of the adult volunteer training program are discussed, and changes to the ways in which relationships are fostered and understood in the organisation are outlined. The review has led to new understandings that modern volunteering requires changes to the ways in which organisational relationships are managed and supported, with a move away from compulsory ongoing training to a focus on volunteers as lifelong learners. Above all, this article shows how productive organisational relationships are when underpinned by founding relationships on openness and honesty, supporting relationships using learning and development, and building relationships using a quality people-management framework.

\section{Introduction}

Girl Guides Australia (GGA) is a values-based not-for-profit organisation, delivering volunteer-led youth programs for girls and young women aged from five to thirty years. Our young member-driven programs use outdoor and indoor educational activities to support development of leadership and decision-making skills. GGA is funded predominantly by membership, but is also supported by grants from business, community and various levels of government. It consists of seven associations across the states of Queensland, Victoria, New South Wales, South Australia, Western Australia and Tasmania, and the Australian Capital Territory and Northern Territory. The seven associations work together as a federated 
national organisation. Girls and young women of about the same age meet together in groups on a weekly basis to enjoy a program of activities that support them to be confident, resilient, self-respecting and responsible community members. The programs are facilitated by volunteer adult leaders who complete training and other development activities to gain the GGA leadership qualification.

In 2011, GGA embarked on the biggest review of its adult volunteer learning and qualification framework undertaken in over a decade. Three key problems drove this review. First, we had a large portion of unqualified leaders delivering our youth programs, putting our reputation and program quality at risk. Second, right across Australia, our youth and adult member numbers were declining but in the places where our member numbers were growing, anecdotal evidence suggested this was due to having effective, well-trained and well-supported leaders in place. We needed to identify the components of the training and ongoing support these leaders were receiving that was driving their effectiveness. Finally, our data showed that the average leader was taking three years to gain the GGA qualification, which was a problem because the average commitment of a volunteer was between two and three years; this meant many were leaving without any formal recognition for the skills they had developed.

In this article, I reflect on the journey that GGA has taken over the past five years to address these three problems. For four of those years, I was part of the team that drove the review, redeveloped the adult volunteer learning and qualification framework and implemented strategies to improve the training of new volunteers. Importantly, this review went beyond simply evaluating volunteer training by making a large number of recommendations aimed at improving the overall volunteer experience and the relationship between those who manage the organisation and those who deliver the program. I focus my exploration on the practices necessary for relationship strengthening, and argue that without strong relationships in voluntary organisations such as GGA, people become disconnected, increasing the volunteer turnover rate, recruitment and training costs and, most importantly, reducing the quality and accessibility of programs. As I explore this argument, I outline the review recommendations, subsequent strategies implemented and their effectiveness across the three core practices we identified as essential for developing strong relationships: founding relationships on openness and honesty; supporting relationships using learning and development; and building relationships using a quality people-management framework. As I reflect on what I learnt through this review process, I also examine the narrative links to be made with the good practice principles for youth development that Girl Guides Queensland (GGQ) helped to develop (Seymour 2012). While these two processes - the review and the framework development - occurred independently of each other, the concurrence of themes across these two instrumental works helps to validate the importance of good practices that support the development of strong, positive relationships in voluntary youth organisations.

\section{Method}

The review was overseen by a steering committee consisting of the National Executive Officer of GGA, CEO Girl Guides Victoria, National Operations Manager, National Learning and Development Manager and the National Program 
Manager and an external consultant. We used a mixed-methods approach comprising a literature analysis, semi-structured interviews, discussion groups and two nationwide quantitative surveys. The literature analysis explored best practice in other guiding and scouting organisations from within Australia and overseas, as well as reviewing current GGA and state organisation published and unpublished documents. Interviews and discussions were held with over 90 stakeholders including members of the national board, state and national learning and development managers, trainers, experienced leaders and new leaders from across Australia. The issues that emerged from the interviews and group discussions formed the basis of two electronic surveys for leaders and trainers. GGA's volunteer trainers were vital to the review as they had first-hand knowledge of the challenges faced by new volunteers and the shortfalls of the current qualification system. The trainers were experienced program leaders and mentors themselves, and provided not only initial training but also ongoing training to volunteers in all areas of the organisation using a learner-centred approach. Just under one-third (31 per cent, or 1,161) of leaders participated in the Leader Survey and almost all trainers (90 per cent, or 114) participated in the Trainer Survey. The research data were reviewed by the external consultant who worked with the steering committee to develop the review report, which included over 100 recommendations (Parish, 2012). All recommendations were put to the GGA Board for consideration before being approved and passed to the National Learning and Development Committee for implementation.

\section{Laying the foundations for an open and honest relationship}

The review process demonstrated how important it is that we practise effective communication practices that support the development of open and honest relationships. We realised that major changes were needed in the ways we communicated in order to improve the volunteer experience and to successfully foster strengths-based relationships between volunteers and GGA. The need for better communication was particularly apparent in two areas where a high level of miscommunication was having negative consequences for GGA.

We discovered that many volunteers were joining GGA on the basis of the misguided idea that the role of program leader only required a two-hour weekly commitment. In reality, the program leader role requires more than a weekly two-hour direct program-delivery commitment. Being a successful program leader requires additional time commitments of program preparation, monthly meetings with other volunteers in the local area, weekend program activities such as camps, recordkeeping, and ongoing training and development. We also discovered that there was a misconception that the only volunteer option in GGA was to be a program leader. This confusion resulted from all adult volunteers being referred to as leaders, resulting in management roles being seen as an extension of the program leader role. In reality, there are different volunteer opportunities in GGA across management and program leader roles. The review highlighted key differences between these two types of roles and the different skills required to carry them out well.

When a match of skill to role is not made and there are misunderstandings about how much time is required, our experience shows a volunteer is unlikely to enjoy their role. This leads to wide-ranging negative consequences for the volunteer, their colleagues, young people and GGA. These negative consequences - which may 
require ongoing corrective action by the volunteer's line manager - can range from volunteers being unable or unwilling to fulfil the duties of the role to which they have been appointed to poor youth program delivery and/or poor management of others. Unfortunately, we had contributed to this misconception, requiring aspiring and existing leaders to consult numerous publications to get the full picture about the real time commitment and expectations, and by not making a clear distinction between different volunteer roles.

The first major change we needed to make was to develop clear volunteer pathways for both youth program delivery and management to allow for more flexibility, specialisation and varying levels of involvement (GGA 2015b). To support the pathways, clear position descriptions have been developed for each role that outline the responsibilities, characteristics and skills required, and channels of communication. These are written in simple, easy-to-understand language; to clearly articulate the true nature of management roles, the term 'Manager' was included in the position title instead of 'Leader'. All promotional materials have been reviewed to ensure that they provide an accurate and honest picture of the time and role commitments required to volunteer with GGA. The adoption of a more ethical approach to promotion is in line with the ethical promotion principle of the Good Practice Principles for Youth Development Organisations (Seymour 2012), where organisations are encouraged to establish an ethical framework to guide promotional decision-making. This move towards a clearer recruitment process that is more accessible to a diversity of people reinforces GGA's commitment to inclusivity, which is one of the principles of good practice in youth development. Local managers now receive training on recruitment and the best way to match volunteers to the most appropriate role.

The second major change we have made is to add a new layer of communication with the addition of clear and detailed inductions for all new volunteers to the organisation and volunteers starting in a new area or a new role. This change helps to ensure that GGA expectations and volunteer responsibilities are clear. The induction covers the GGA Code of Conduct for Adults; the position description; police and child protection checks; organisational policies and procedures; an introduction to the team with which they will be working; supply or location of resources; and the appointment of an appropriately skilled person to support and mentor their learning and development in order to complete the relevant qualification (GGA 2015a). The good practice principles encourage the organisation to provide easy access to support and mentoring as part of an effective learning and development program. Where possible, the induction also includes a handover from the predecessor and clear direction from the line manager on tasks that require priority action to ensure Guiding in the local area continues to flourish. By completing such a detailed induction, GGA is setting the volunteers up for the best possible experience with the organisation, giving them the tools they need to be successful in their role and building a solid foundation for a long-term relationship.

\section{Supporting the relationship through learning and development opportunities}

The review highlighted significant problems with our approach to learning and development that were contributing to leader dissatisfaction and our low 
volunteer-retention rates. Our existing volunteers made it clear to us that there were significant misunderstandings about what a volunteer needed to do to become a qualified GGA leader. Just over one third (39 per cent, or 96) of recently qualified leaders stated that they had been clear about what they needed to do to gain their leader qualification upon joining the organisation. The review revealed to us that our qualification process was too complicated, inaccessible and unclear; consisting of a number of different components, depending on the volunteer role. These components were often not directly relevant to the work the volunteer was doing. For program leaders, there was also a disconnection between their learning and development opportunities and the activity skills they needed to be able to meet their Guide group's interests. The Good Practice Principles for Youth Development Organisations (Seymour 2012) highlight the need for the learning and development within the organisation to reflect the core values, skills and knowledge needed by program leaders. Ongoing and relevant learning and development are crucial if a youth program is to stay relevant to and engaging for volunteer leaders and their Guides group. We also learnt that there was a lack of recognition of prior learning, with less than one-quarter (23 per cent, or 267) of leaders feeling there was enough recognition of the skills they brought with them. This was particularly frustrating for volunteer leaders with teaching or youth program delivery expertise.

Since the review, we have implemented a number of changes to address these problems. We have developed one training document per role. Each role training document, referred to as a passport, is tailored to the needs of the role, and clearly outlines exactly what is required to gain the relevant GGA qualification (GGA 2015b). The passport lists the qualification requirements in a way that the volunteer, their mentor and the line manager can view and track the progress of the volunteer through a variety of practical activities, recommended readings, faceto-face training and personal reflection that focus on the key basic tasks needed to be successful in the role. Making the provision of learning and development opportunities a high priority for new program leaders is an essential requirement for a quality youth program under the Good Practice Principles for Youth Development Organisations.

We have also adopted individual learning plans, which are now developed for each volunteer prior to their beginning any training and development activities. These plans recognise that each person is unique and brings valuable skills to the organisation. The development of individual learning plans is another of the indicators of a quality learning and development program as outlined in the Good Practice Principles for Youth Development Organisations. The initial learning plan is developed by the volunteer's mentor after her induction is complete and before she commences on the requirements of the relevant qualification, and focuses on the completion of the qualification (GGA 2015b). Clear guidelines on the recognition of prior learning (RPL) have been developed so that mentors can grant volunteers automatic recognition for skills they bring with them - another important practice enshrined in the Good Practice Principles for Youth Development Organisations. If a mentor is uncertain, they are able to contact a RPL specialist in their state or territory, thus ensuring an effective and consistent application of the RPL guidelines across Australia. The mentor works with the volunteer to ensure they understand what is required to gain their qualification, develops plans for the completion of the qualification requirements, and sets an estimated date for the completion of the qualification. 
Resources in the form of Leader and Manager Handbooks and Youth Program Handbooks have also been developed as a program foundation. GGA has removed mandatory post-qualification training and development in set areas. Now we encourage volunteers to develop their skills in areas of the program in which they or the Guides with whom they work are interested, such as outdoor activities, multiculturalism, the arts, environmental protection or community service. Learning opportunities are offered and delivered to volunteers in a way that encourages them to take charge of their own learning and develop the skills for lifelong learning. By giving volunteers the program foundation in the form of handbooks, allowing them to make choices about their further development, then encouraging and supporting those choices, we are seeing better program outcomes with reports of girls participating in a wider range of engaging program activities on a regular basis.

\section{Supporting and monitoring the relationship}

A relationship needs to be both supported and monitored if it is going to continue to be positive and long term. The volunteer-appraisal process was one of the major areas of dissatisfaction identified by the review. Under the previous appraisal system, many leaders were only given feedback every three years when it was time to complete their appraisals. Where there were issues of concern or risk, such as declining membership within a unit, incomplete financial records or poor behaviour towards other volunteers, this was often left until the appraisal or simply not dealt with at all. When the appraisal process did take place, it was seen to be rushed and as failing to focus on how the individual was performing in their role. One of the major concerns raised by volunteer staff was the fact that the line manager was not necessarily directly involved in this appraisal process.

The review recommended that appraisals be carried out by the person to whom the leader is responsible; however, for this to happen there needed to be better training of managers. In designing the manager qualification, specific training and development activities were included in relation to people management and the completion of reviews - the term by which appraisals would now be known. Reviews are now carried out six months after the completion of a qualification or appointment to a new role, and become annual thereafter. The review has been developed to be open and inviting, to celebrate each person's achievements and to identify areas where existing skills and knowledge could be developed further and new skill and expertise areas explored within their role, including new roles or areas of responsibility, and/or developing skills in other program areas. The result is a new individual learning plan for the volunteer for the following twelve months.

Another key piece of work completed by GGA following the review was the development of a People Management Framework that encourages managers to provide feedback in a timely manner and enables issues of concern to be dealt with appropriately and not left until the review. Every volunteer now receives training about how to give strength based feedback to others and to understand the support that is available when there are issues of concern or risk. The framework endorses the provision of both informal feedback for support, recognition or early challenge and conflict resolution, and formal feedback in the form of the six-month postqualification reviews and annual reviews. This framework has helped GGA to create 
a more supportive and positive environment for our volunteers, aiding in the overall development of an inclusive ethos as recommended by the Good Practice Principles for Youth Development Organisations. Since this framework was implemented, feedback from our volunteers tells us that volunteers look forward to their annual review, get excited about sharing what they have achieved in their role and are starting to take responsibility for their own further learning. They are also more willing to talk about the challenges they are experiencing and more accepting of support and suggestions for improvement.

\section{Conclusion: The future}

To date, the review process I outlined in this article and the changes we have implemented in response to the review recommendations have had a positive effect on GGA. We have learnt that Guiding thrives in local areas where volunteers fully understand their role, where managers have developed open and honest relationships with those with whom they work, where feedback is given and potential issues are dealt with in a timely manner, and where volunteers are consistently and continuously recognised for their contribution, whether it be in program delivery or management. From experience, we know that when leaders are given choices about their training and development, they develop a positive attitude towards learning, which results in a higher quality and more innovative program that girls and young women will find engaging and empowering. Our experience has also shown us that volunteers who enjoy what they do are more committed to the organisation's aims and objectives, deliver highly effective programs to youth members, and require much less intervention and corrective action by their line manager.

The changes we have implemented over the past five years for volunteers in GGA have not come without hurdles. These changes are significant and we have needed to manage these changes respectfully and carefully. Effective communication each and every step of the way has been crucial in helping us to prepare members for change. While our first big hurdle was convincing members that there was a need for change the review statistics clearly demonstrated why GGA had to change. Once people accepted our need for change, we were able to introduce change slowly, commencing with our largest group: those who delivered the program to youth members. We knew that this group was where we would gain the greatest traction and acceptance, as well as where we could address the majority of core problems highlighted by the review.

We have learnt that it takes a great deal of energy and time, and considerable financial resources, to implement such wide-reaching changes and to establish, support and grow relationships. We hope that by adopting a continuous improvement approach, the urgent and critical need for such extensive change will never happen again. Now we are able to identify when we need to make changes and change has become a normal part of our work. Our policies, procedures and documents are amended in a timely manner, enabling issues with recruitment, training and development, and monitoring volunteer relationships to be dealt with as and when needed. Anecdotal and membership data are now showing us that new leaders are thoroughly enjoying their qualification journey, and those in management roles are far more effective, with more areas demonstrating sustained membership growth. 


\section{Acknowledgements}

Present and past members of the National Learning and Development Committee of Girl Guides Australia; Helen Reid, National Program Manager of Girl Guides Australia; Kim Parish, External Consultant on the Girl Guides Australia Learning and Development Review; Kathryn Seymour, Guest Editor; Girl Guides Queensland and Girl Guides Australia.

\section{References}

Girl Guides Australia 2015a. Leadership qualification passport, 4th ed. Sydney: Girl Guides Australia.

Girl Guides Australia 2015b. Qualification passport guidance notes, 2nd ed. Sydney: Girl Guides Australia.

Parish K. 2012. A report for Girl Guides Australia on the Australian Adult Leadership Program and the Australian Trainers Training Program. Sydney: Girl Guides Australia.

Seymour K. 2012. Good practice principles for youth development organisations, 2 nd ed. Brisbane: Key Centre for Ethics, Law, Justice and Governance, Griffith University. 